\title{
Sanitarian becomes ecologist: the new environmental health
}

\author{
Sensitivity to the environment demands new skills and attitudes
}

Once again public health is on the move. After 40 years in which medical thinking has been dominated by the "magic bullet," therapeutic, model of health the pendulum has swung strongly in the direction of health promotion and preventive medicine.

The reasons for this shift are complex. They include the prevailing political philosophies, which are antipathetic to publicly funded services and emphasise personal responsibility. But they also include various strands of academic support. These range from Ivan Illich's indictment of the iatrogenic effects of much of medical practice to the abundant evidence that, despite enormous investment in medical care, the health of large sections of the population has failed to show commensurate improvement. ${ }^{1}$ Not least is McKeown's demonstration that most of the improvement in mortality in England and Wales between 1840 and 1970 had occurred before the availability of effective treatments. ${ }^{2}$ McKeown's claim that the main contributions to improved health came from (in order of importance) limitation in family size (a behavioural change), increase in food supplies and a healthier physical environment (environmental influences), and specific preventive and therapeutic measures has had a particularly strong influence around the world.

The World Health Organisation's strategy of Health For All by the Year 2000 and its setting of targets for health improvement through initiatives such as the healthy cities project have provided a framework and powerful legitimation for the revived emphasis on public health..$^{3-5}$ Recently both the Acheson report Public Health in England and the Institute of Medicine's report on the future of public health in the United States have highlighted the extent to which routine public health systems and practice have been neglected since the war. ${ }^{67}$ In Britain the government white papers Promoting Better Health and Working for Patients have both given much greater emphasis to public health and prevention than before. ${ }^{89}$ Indeed, under the new arrangements the public health function becomes central to the district health authority's role.

The separation of the roles of provider and purchaser frees the health authority and its director of public health to take an overview of the population's health and conduct the orchestra of individual, collective, and organisational responses to tackling the problems revealed. The implications of these developments for the traditional partners in public health are considerable, not least for environmental health officers, who were so central to the old public health, with its emphasis on hygiene, pollution, and the prevention of infectious disease.

The Victorian public health movement was constructed around a powerful motivating concept that came to be known as the "sanitary idea": the idea that overcrowding in insanitary conditions was at the root of the epidemics that afflicted the great towns and cities. ${ }^{10}$ In the 1840 s, 30 years before the germ theory of disease, it was this idea that led to the 1848 Public Health Act and the establishment of municipal departments of public health, with city medical officers and sanitary inspectors working as a team. The sanitary idea, coupled with the enlightened self interest of the middle classes in recognising their vulnerability to cholera spreading from poor neighbourhoods, also generated the momentum for adequate housing, safe water, and sewage disposal. In retrospect, the sanitary idea may be seen to have been flawed and incomplete and a product of Victorian thinking that technical solutions could be imposed on natural systems. A constant stream of man made problems, including bovine spongiform encephalopathy and the greenhouse effect, should serve as a warning of the limitations of this approach. Similarly, when only a few, comparatively small, European cities were affected moving sewage and solid waste away from its origin and abandoning it in rivers and landfill sites might have worked. But when a much greater proportion of a much bigger world population is implicated this is a recipe for ecological disaster: the carrying capacity of even the big biological systems is just not great enough.

One outcome of the renewed interest in public health in the 1980s has been a widespread raising of awareness about the part that personal lifestyle plays in generating ill health. This emphasis is now rapidly giving way to a focus on green issues and the environmental components that are indivisible from lifestyle in an understanding of health as an ecological idea. ${ }^{11}$ The concept of reciprocal maintenance - that we should look after the things that look after us-is rapidly gathering ground, whether those things are our own bodies or the planet itself. $^{12}$

A recent WHO workshop identified four principles from ecological science that should be followed in developing ecologically sound communities. ${ }^{13}$ The first is that civic design, agriculture, and other human interventions should aim as far as possible at working with the natural topography and biological systems, rather than mechanically imposing themselves on them. Working with the natural characteristics 
of an environment brings benefits for drainage and water supply, ventilation, insulation, indoor climates and microclimates, and, not least, the aesthetic appreciation of people using that environment.

Secondly, diversity and variety should be aimed at in the physical, social, and economic structuring of communities. Land uses should be mixed where this does not create hazards. Monolithic housing estates should be a thing of the past, and increasing integration between work, residence, and leisure should reduce the volume of traffic and its associated danger and pollution.

Thirdly, artificially created systems should be as closed as possible. This principle applied in environmental management would mean that human and solid waste is recycled locally wherever possible and that there is a shift towards renewable sources of water, energy, and raw materials.

Lastly, there should be an optimal balance between population and resources. Urban and population change needs to be related to the fragile state of natural systems and the environments that support them. The need for this sensitivity should be clear from looking at the effects on the infrastructure and natural environment of unplanned population movements in the south east of England and similar megalopolises where regional planning has been abandoned.

As we mark the 100th anniversary of Edwin Chadwick's death, his spiritual heirs in environmental health, public health medicine, and related occupations are faced with a challenge at least as great as that which faced him. Over many decades, the work of public health pioneers has been defined and codified, frozen in relation to another era and another way of looking at the world. Its practice now seems to have become reactive and bureaucratic, rather than proactive and innovative. Practitioners of the new public health need to have a good grounding in ecology and a vision of how to reconcile the natural and the built environments. They need to revisit all the topics of the old public health-housing, food, water, sanitation, education, occupation, transport, genetics and microbiology, and medical and social services - and to reexamine them with ecological eyes. This has considerable implications for the education and training and for the work patterns of those who work in public health, not least for those whose roots lie in environmental health. There is, particularly, a need for new multidisciplinary initiatives in both training and working.

It remains to be seen whether the sanitarians can respond by incorporating the ecological idea into their thinking and practice and developing broad based coalitions to tackle the global and local problems that face us. Already the WHO healthy cities project and similar initiatives are providing a vehicle for the new breed of practitioners to make their mark by bringing together all those who can influence health and the environment to agree an agenda for the 1990s.

JOHN ASHTON

Senior Lecturer in Public Health,

University of Liverpool,

Liverpool L69 3BX

1 Illich I. Medical nemesis. London: Marion Boyars, 1975.

McKeown T. The role of medicine -dream, mirage or nemesis. London: Nuffield Provincial Hospitals Trust, 1976.

World Health Organisation. Global strategy for health for all by the year 2000. Geneva: WHO, 1981

4 World Health Organisation. Targets for health for all. Copenhagen: WHO, 1985.

Ashton J, Grey P, Barnard K. Healthy cities: WHO's new public health initiative. Health Promotion 1986;1: 319-24.

6 Department of Health. Public health in England. London: HMSO, 1988. (Acheson report.) (CM 289.)

7 Institute of Medicine. The future of public health. Washington, DC: National Academy Press, 1988 8 Secretaries of State for Health, Wales, Northern Ireland and Scotland. Promoting better health Lecrar

Secretaries of State for Health, Wales, Northern Ireland and Scotland. Working for patients. London: HMSO, 1989. (Cmnd 555.)

London: HMSO, 1989. (Cmnd 555.)
Chadwick E. The sanitary condition of the labouring classes. Facsimile edition. Edinburgh: Edinburgh University Press, 1965 (1842).

11 Bruntland GH, ed. Our common future: the report of the World Commission on Environment and Development. Oxford: Oxford University Press, 1987.

2 Lovelock J. The ages of Gaia-a biography of our living earth. Oxford: Oxford University Press, 1989. (Report of a workshop held in Liverpool, 1988.

13 World Health Organisation. Ecological models for healthy cities planning. Copenhagen: WHO, 1988. EUR/ICP/RUD114.

\section{Psychotropic drugs for problem children}

\section{Need specialist supervision}

Are there good indications for the use of psychotropic drugs in children? Adams's retrospective study of the prescribing habits of general practitioners and consultant child psychiatrists concludes that these drugs are sometimes inappropriately used in children, may be dangerous, and should be avoided whenever possible (p 217).

Psychotropic drugs may interfere with a child's growth, learning, and family functioning. They may mask symptoms, and they may encourage a child to turn too readily to pills to solve personal problems rather than to seek a solution from an expanding repertoire of problem solving strategies. They may foster dependency on authority figures at the very time that adolescents should be struggling for independence. ${ }^{2}$

Research on psychopharmacology in children is in its infancy. Yet there is good evidence that some drugs are effective. Although probably overdiagnosed, the hyperkinetic syndrome is a troublesome and handicapping child psychiatric disorder which responds better if a stimulant drug, methylphenidate, is added to psychological treatments. ${ }^{3}$ Likewise, obsessional disorder, a serious emotional disorder that leads to considerable dysfunction in children and adolescents, may be considerably improved by adminis- tering clomipramine, a tricyclic antidepressant. ${ }^{4}$ Tics or habit spasms, especially of the vocal kind (Gilles de la Tourette's syndrome), respond to haloperidol. ${ }^{5}$ Major depressive disorders in adolescents may require treatment with tricyclic antidepressants and, if bipolar, lithium carbonate. ${ }^{6}$ Early onset schizophrenia requires the use of phenothiazine medication as in adults, but there have been few controlled trials in children.

Yet none of these conditions are those for which psychotropic drugs are commonly prescribed in childhood. Adams found that psychotropic drugs were most often used for enuresis and insomnia, two childhood problems commonly seen by general practitioners. ${ }^{1}$ For both conditions there are effective behavioural and other treatments, so drugs should never be used as a first line of treatment because of their side effects and the danger of toxicity in overdose (either accidental or deliberate). They may, however, be effective when other treatments have failed if used as part of a comprehensive treatment plan that includes psychological treatments and limits the period of medication. Imipramine has been shown in controlled trials to have a short term benefit in nocturnal enuresis, although an enuresis alarm may be more perma- 